\title{
Characterization of Petroleum Compounds Adsorbed on Solids by Infrared Spectroscopy and Mass Spectrometry
}

Santiago Villabona-Estupiñan, ${ }^{\dagger \dagger}$ Jose L. Pinto-Camargo, ${ }^{\dagger \dagger}$ Eduardo J. Manrique-Ventura, ${ }^{\dagger}$ Jorge A. Orrego-Ruiz, ${ }^{* *}$ Fernando A. Rojas-Ruiz ${ }^{* *}$

† ECOPETROL, Instituto Colombiano del Petróleo, Piedecuesta, Santander 681018, Colombia.

\#Universidad Industrial de Santander, Grupo de Investigación Recobro Mejorado, Bucaramanga, Santander, Colombia.

\section{SUPPORTING INFORMATION:}

For comparative purposes, Figure S1 shows the spectra of all samples superposed with DCM. The spectra were acquired after evaporation of solvent, as evidenced by the disappearance of the DCM signals.

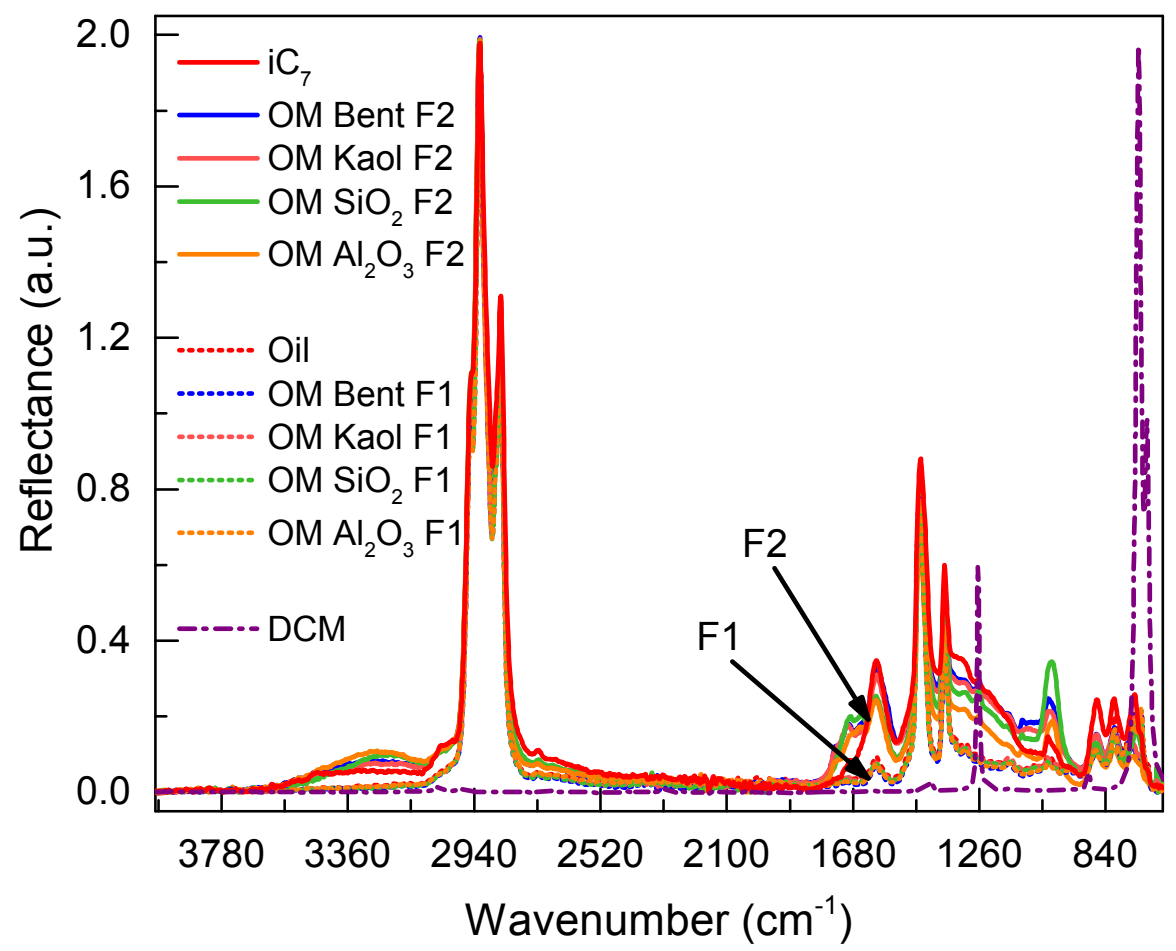

Figure S1. Spectra superposed with the solvent spectra (DCM) used for deposition on the diamond cell in the ATR FT-IR instrument. 
In Figure S2 can be seen that the contribution of hydroxylated species for OM samples is even higher than $\mathrm{iC}_{7}$ and undetected in the crude oil, while the aromatic species are in higher concentration for $\mathrm{iC}_{7}$ than $\mathrm{OM}$ samples.

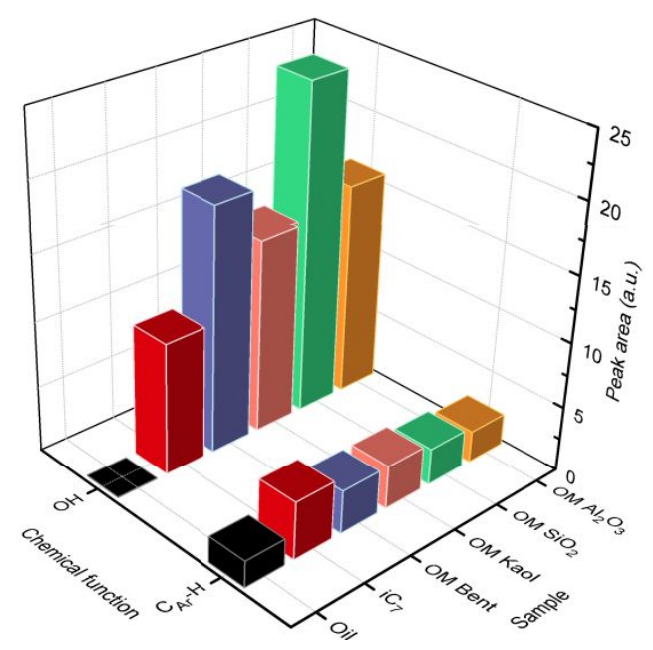

Figure S2. Peak area representation of bands atributted to $\mathrm{OH}$ and $\mathrm{C}_{\mathrm{Ar}}-\mathrm{H}$ groups as a funtion of sample 
Figure S3 summarizes the areas calculated for the range $1800-1500 \mathrm{~cm}^{-1}$, and includes hypothetical structures associated with each peak. Dotted circular lines indicate structural diversity around aromatic moieties.

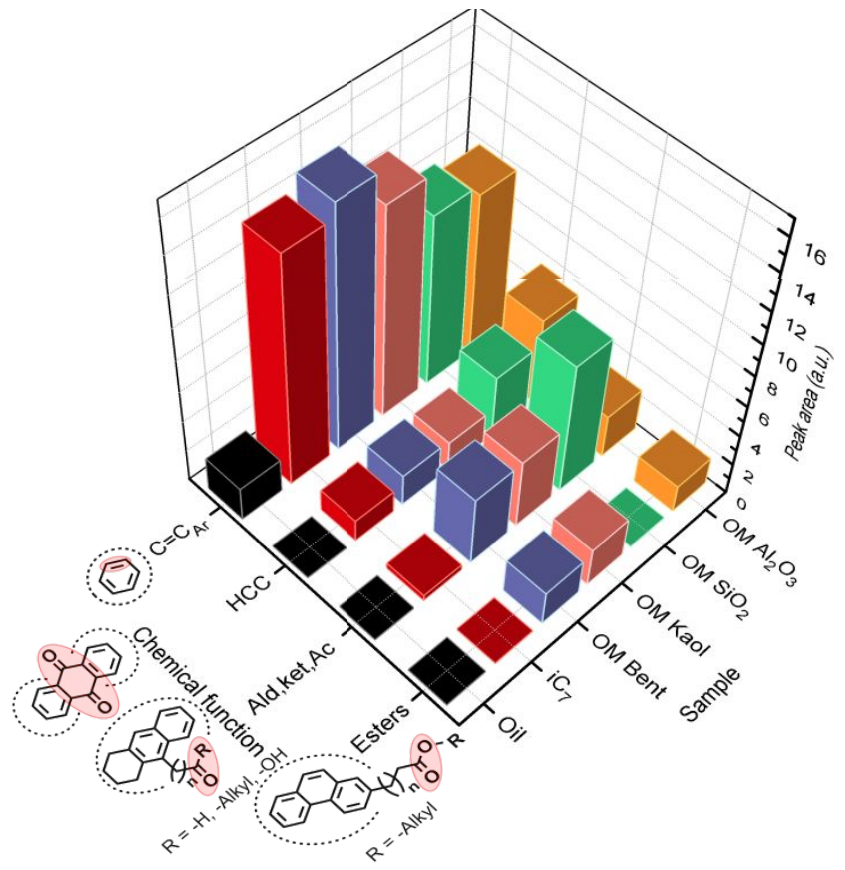

Figure S3. Peak area representation of bands atributted to $\mathrm{C}=\mathrm{O}$ and $\mathrm{C}=\mathrm{C}_{\mathrm{Ar}}$ groups for samples.
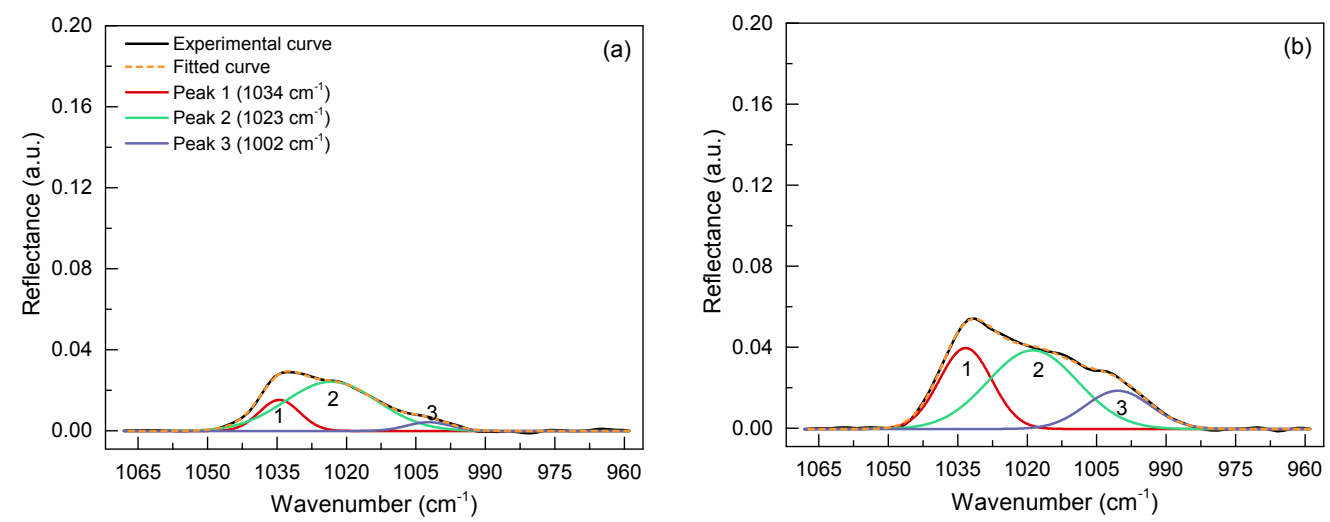

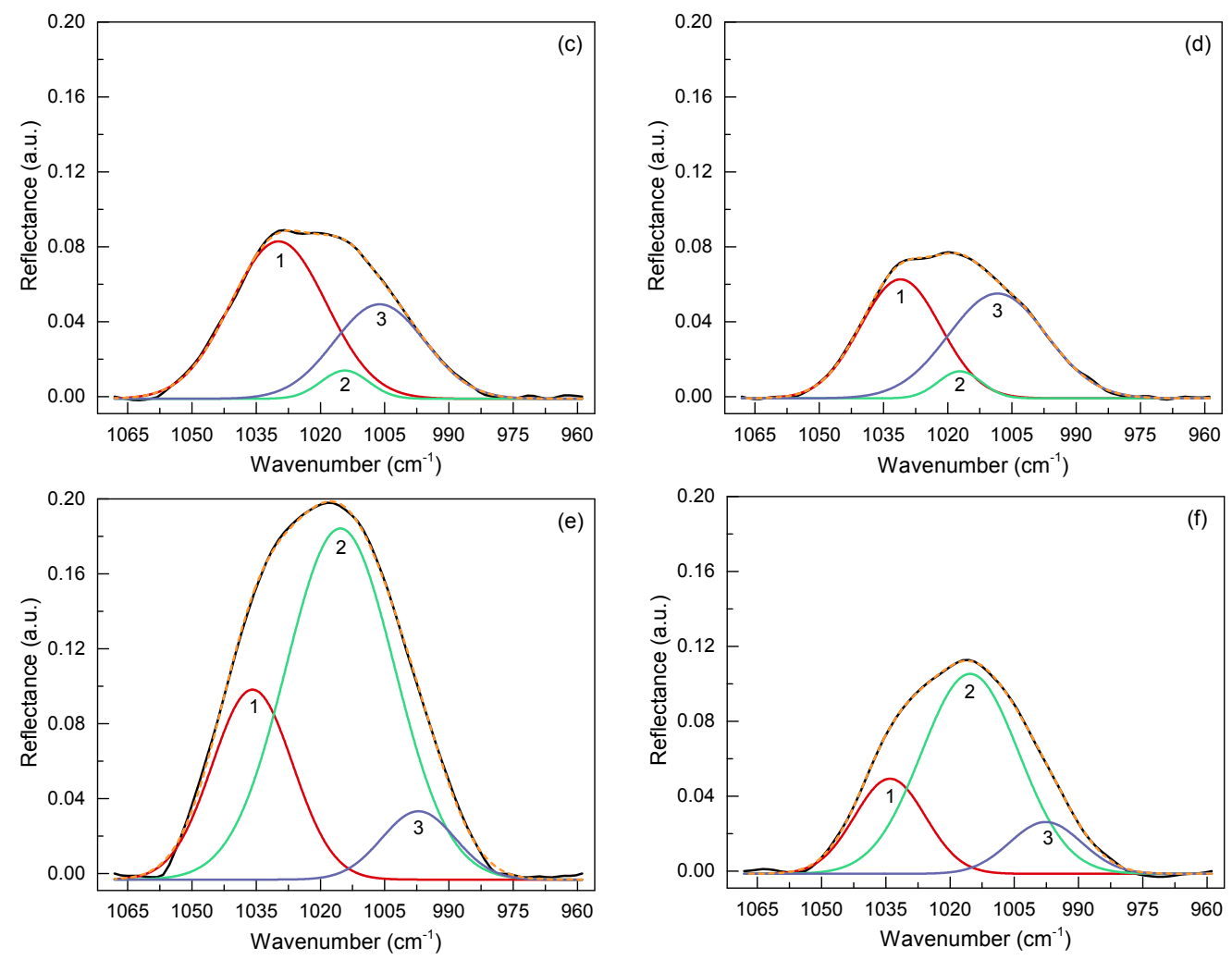

Figure S4. IR espectra deconvoluted region $\left(1070-960 \mathrm{~cm}^{-1}\right)$ focused to characterize the $v(\mathrm{~S}=\mathrm{O})$ bands from samples: a) Oil, b) $\mathrm{iC}_{7}$, c) $\mathrm{OM}$ Bent, d) $\mathrm{OM}$ Kaol, e) $\mathrm{OM} \mathrm{SiO}_{2}$ and f) $\mathrm{OM} \mathrm{Al}_{2} \mathrm{O}_{3}$

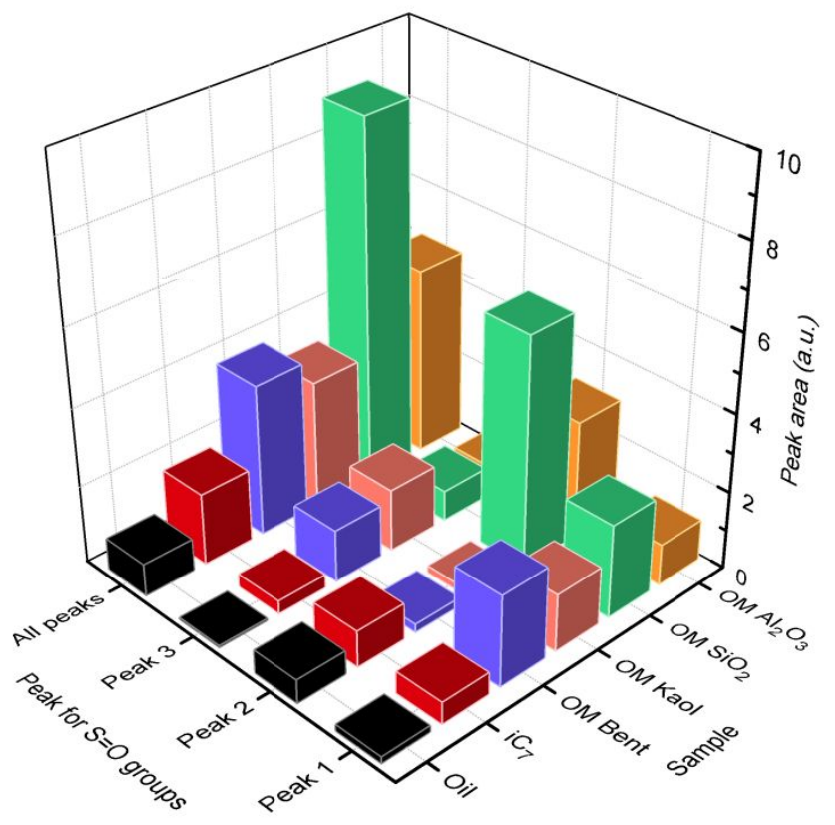

Figure S5. Peak area representation of bands atributted to $\mathrm{S}=\mathrm{O}$ groups 


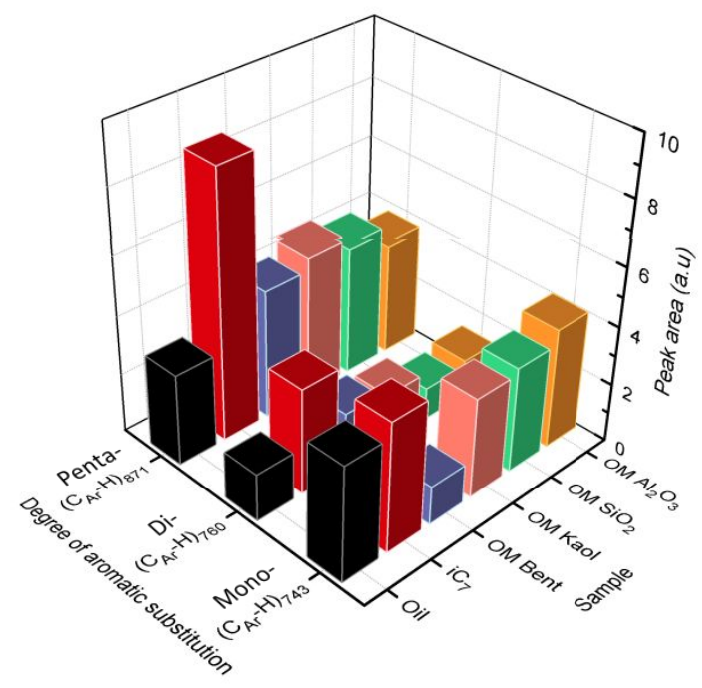

Figure S6. Peak area representation of the $\mathrm{C}_{\mathrm{Ar}}-\mathrm{H}$ bands attributed to mono-, di- and penta-substituted aromatic rings from the deconvoluted region $930-670 \mathrm{~cm}^{-1}$

Figure S7 shows the error distributions for the S1 class detected by $(+)$ APPI for crude oil and fractions F1 and F2. 

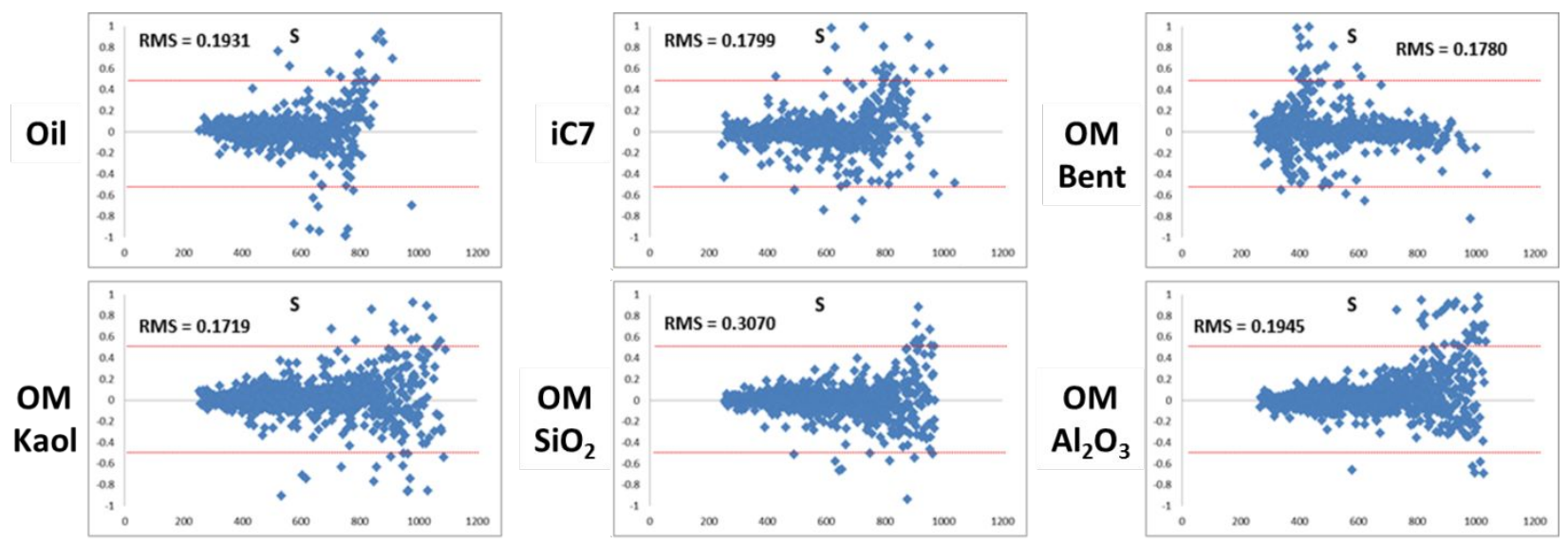

Figure S7. Distribution of error graphs where the $y$ axis is the error (ppm) and the $\mathrm{x}$ axis is the $\mathrm{m} / \mathrm{z}$ for the S1 class detected by $(+)$ APPI FT-ICR MS.

Errors were distributed randomly around cero. However, it can be noticed that in all cases a little bias is observed at $\mathrm{m} / \mathrm{z}>650$. This can be explained considering that quadratic functions were employed for recalibration using Data Analysis, and error does not behave this way in the whole mass range. However, this does not affect the correct assignment of peaks taking into account that the error limits were under 0.5 ppm. 